\title{
Right ventricular dysfunction as predictor of longer hospital stay in patients with acute decompensated heart failure: a prospective study in Indonesian population
}

\author{
Paskariatne Probo Dewi Yamin ${ }^{1,2}$, Sunu Budhi Raharjo ${ }^{1 *}$ D, Vebiona Kartini Prima Putri ${ }^{1}$ and Nani Hersunarti ${ }^{1}$
}

\begin{abstract}
Background: Hospital length of stay (LOS) is a key determinant of heart failure hospitalization costs. Longer LOS is associated with lower quality of care measures and higher rates of readmission and mortality. Right ventricular (RV) dysfunction predicted poor outcomes in patients with stable chronic heart failure (CHF), however, its prognostic value in the acute decompensated heart failure (ADHF) patients has not been sufficiently clarified. This study investigated the prognostic value of RV dysfunction in predicting longer LOS in ADHF patients.
\end{abstract}

Methods: A prospective cohort study was conducted in National Cardiovascular Center Harapan Kita to all patients admitted with ADHF. Clinical data and baseline RV function assessed by tricuspid annular plane systolic excursion (TAPSE) were collected. Clinical comorbidities including malnutrition, pneumonia and worsening renal function (WRF) were monitored during hospitalization. The primary outcome was hospital LOS. Cox regression analysis was used to identify independent predictors for longer LOS.

Results: Two hundred and fifty-nine ADHF patients were included in this cohort study. On time-to-event analysis, diastolic blood pressure $(H R=1.011 ; 95 \% \mathrm{Cl}=1.004-1.018 ; p=0.002)$, hemoglobin levels $(H R=1.102$; $95 \% \mathrm{Cl}=1.045-1.162 ; p<0.001)$, RV function ( $\mathrm{HR}=0.659 ; 95 \% \mathrm{Cl}=0.506-0.857 ; p=0.002)$, WRF $(\mathrm{HR}=2.015$; $95 \% \mathrm{Cl}=1.520-2.670 ; p<0.001)$ and malnutrition $(\mathrm{HR}=5.965 ; 95 \% \mathrm{Cl}=4.402-8.082 ; p<0.001)$ were associated with longer LOS. In a multivariate Cox regression model, RV function ( $H R=0.466 ; 95 \% \mathrm{Cl}=0.238-0.915 ; p=0.026)$, WRF $(H R=2.985 ; 95 \% \mathrm{Cl}=2.032-4.386 ; p<0.001)$ and malnutrition $(H R=7.479 ; 95 \% \mathrm{Cl}=5.071-11.030 ; p<0.001)$ were the independent predictors of longer hospital LOS. Based on the median TAPSE values, patients with TAPSE $\leq 16 \mathrm{~mm}$ had significantly longer $\operatorname{LOS}(\mathrm{HR}=2.227 ; 95 \% \mathrm{Cl}=1.103-4.494 ; p=0.026)$ compared to those with TAPSE $>16 \mathrm{~mm}$.

Conclusions: Right ventricular dysfunction, WRF and malnutrition are important predictors of longer LOS. This is the first study to describe that in ADHF patients, lower the TAPSE resulted in longer the LOS.

Keywords: Acute decompensated heart failure, Right ventricular function, Tricuspid annular plane systolic excursion, Length of stay

\footnotetext{
* Correspondence: sunu.b.raharjo@gmail.com

${ }^{1}$ Department of Cardiology and Vascular Medicine, Faculty of Medicine,

Universitas Indonesia, National Cardiovascular Center Harapan Kita, Jl.

Letjend. S. Parman Kav 87, Slipi, Jakarta 11420, Indonesia

Full list of author information is available at the end of the article
} 


\section{Background}

Despite progress in its treatment, heart failure (HF) is a progressive disease that produces high rates of morbidity and mortality, characterized by frequent hospital admissions and prolonged length of hospital stay [1-3]. Acute decompensated heart failure (ADHF), a condition in which the patients experienced rapid worsening of $\mathrm{HF}$ signs and symptoms, was the major cause of hospitalization in HF patients [4]. Hospital length of stay (LOS) is a key determinant of HF hospitalization costs. Longer LOS is also associated with lower performance on quality of care measures and higher rates of subsequent readmission and mortality $[2,5]$. Therefore accurate prognostic information from determinants associated with increased morbidity, in this case hospital LOS, is required.

Several studies revealed that possible determinants of longer LOS for HF patients include socio-demographic variables, medical comorbidity, disease severity (worse functional class and lower left ventricular ejection fraction), clinical presentation, in-patient treatment, inhospital progress and the development of iatrogenic complications [1, 6-8]. Some medical comorbidities that were known in prolonging LOS are concurrent stroke, worsening renal function (WRF), atrial fibrillation, respiratory problems requiring specific treatment, and malnutrition [1, 8-11].

In the last few years, attention for right ventricular (RV) structure and function in HF patients has rapidly grown. Although less well studied than the left ventricle (LV), the RV may be of equal importance in determining prognosis in HF patients [12]. RV dysfunction has been shown to be associated with an adverse outcome in patients with symptomatic HF [13-15]. While RV dysfunction has been extensively studied in stable chronic HF, its prognostic value in the setting of ADHF patients has not been sufficiently clarified. Several studies have been conducted with contradictory results [16-18]. Accordingly, this study sought to investigate the prognostic value of RV dysfunction as assessed by TAPSE, and other echocardiographic and clinical comorbidities in predicting longer LOS in ADHF patients.

\section{Methods}

\section{Patients}

This was an observational, prospective cohort study that included ADHF patients aged 18 and above that were hospitalized consecutively in National Cardiovascular Center Harapan Kita (NCCHK) between December 2014 and February 2015. The study was approved by our hospital's ethical committee.

Diagnosis of ADHF was established according to the recommendations of the European Society of Cardiology (ESC) [19]. Patients were excluded if they had an evidence of acute coronary syndrome, primary valvular heart disease, congenital heart disease, heart failure post valvular and congenital heart surgery, cardiac tamponade, aortic dissection, acute pulmonary embolism, and did not consent to participate in this study. We also excluded patients with severe tricuspid regurgitation on echocardiography examination. Patients who died during hospitalization were also excluded from the study.

\section{Measurements and study procedures}

Baseline and clinical characteristics, anthropometry status, and laboratory data were collected during hospital admission. Clinical comorbidities such as worsening renal function (WRF) and respiratory infection (pneumonia) were monitored during patients' hospitalization. WRF is the occurrence, at any time during the hospitalization, of $\geq 0.3 \mathrm{mg} / \mathrm{dl}$ or $\geq 25 \%$ increase in serum creatinine from admission [20]. Estimated glomerular filtration rate (eGFR) was calculated by the Modification of Diet in Renal Disease (MDRD) equation that has been shown to be the best method for the indirect assessment of renal function in HF patients [21].

\section{Nutritional assessment}

For evaluation of malnutrition, nutritional status was assessed using Nutritional Risk Index (NRI) formula as follows: [1.519 $\times$ serum albumin $(\mathrm{gr} / \mathrm{L})+41.7$ (current weight/ ideal weight)] [22, 23]. Ideal body weight was calculated using the Lorentz formula [24] for men $=$ [height $(\mathrm{cm})$ 150]/4] and women $=[$ height $(\mathrm{cm})-150] / 2]$. Ideal body weight was used instead of usual body weight because it was less subjective. Subjects were classified as having malnutrition if their NRI score was less than $97.5[25,26]$.

\section{Echocardiographic measurements}

Echocardiography examination was performed in the ward within the first $48 \mathrm{~h}$ after admission, depends on patient's clinical condition. It was performed in accordance with the recommendations of the American Society of Echocardiography [27]. LVEF was calculated from apical two- and four-chamber views using the modified Simpson's rule. RV systolic function was evaluated by Mmode echocardiography using TAPSE. TAPSE was measured on M-mode tracing at the junction of the tricuspid valve and RV free wall in the apical four-chamber view [13]. Data were averaged over 3 beats ( 5 beats in cases of atrial fibrillation).

\section{Study outcomes and definitions}

The primary outcome in this study is hospital length of stay. Hospital LOS was defined as the actual number of days the patients remained in the hospital, determined from the day of admission to the moment of discharge. 


\section{Statistical analysis}

Statistical analysis was performed using SPSS program. Continuous variables are presented as the mean \pm standard deviation, or median (minimum-maximum) if not normally distributed. Categorical variables are presented in frequency (percentages). Univariate analysis was performed to identify the variables associated with LOS, including age, clinical characteristics (congestion signs, ischemic etiology, history of hypertension, history of prediabetes/diabetes, atrial fibrillation, systolic blood pressure, diastolic blood pressure, heart rate), laboratory values (hemoglobin, baseline eGFR, random blood glucose), echocardiographic measurements (LV End Diastolic Diameter, LV End Systolic Diameter, LV Ejection Fraction, TAPSE, Mean Pulmonary Artery Pressure), and comorbidities during hospitalization (pneumonia, malnutrition, worsening renal function). Those variables with $p<0.25$ at the univariate analysis were included in the multivariate model. Backward stepwise selection was then performed to identify independent prognostic factors for hospital LOS. A p value of $<0.05$ was considered to be statistically significant. Results are presented as hazard ratios (HR) with confidence interval of $95 \%$.

\section{Results}

\section{Patients characteristics}

Of a total of 265 ADHF patients that were initially included in this prospective cohort study, 6 patients died during hospitalization period. The 259 study patients had a median age of 59 years old, $74.9 \%$ were male, and $74.1 \%$ had LVEF less than $40 \%$. Sixty-six percent of patients had prior hypertension, $60.6 \%$ prediabetes/diabetes, and $49 \%$ had a risk factor of smoking. Acute lung edema was diagnosed in 19 (7.3\%) patients and ischemic etiology as the cause of heart failure was discovered in 198 (76.5\%) patients. Forty-nine percent of patients were classified as having malnutrition based on NRI value obtained at hospital admission. There were 31 (12\%) patients that experienced concomitant acute respiratory infections (pneumonia) requiring specific antibiotic therapy and $72(27.8 \%)$ developed worsening renal function during the course of hospitalization.

During hospital admission, almost all of the patients received intravenous loop diuretics (91.9\%), and an angiotensin converting enzyme inhibitors (ACEi) $(56.4 \%)$ or angiotensin receptor blockers (ARB) (35.9\%). The prescription rates of beta blockers and mineralocorticoid receptor antagonist (MRA) were $46.3 \%$ and $49 \%$ respectively. Whereas the usage of calcium channel blockers (CCB) and digoxin on admission were very low, only $7.3 \%$ and $18.1 \%$ respectively.

The median hemoglobin, leucocyte, random blood glucose and albumin were within normal range for our laboratory value. However the median of ureum and creatinine were higher than the normal range. The median of TAPSE and mean pulmonary artery pressure (mPAP) for the entire cohort was $16 \mathrm{~mm}$ and $25 \mathrm{mmHg}$ respectively. If we divided TAPSE based on median value of $16 \mathrm{~mm}$, there were 139 (53.7 \%) patients with TAPSE $\leq 16 \mathrm{~mm}$ and $120(46.3 \%)$ patients with TAPSE > $16 \mathrm{~mm}$.

Baseline demographic, clinical characteristics, medications on admission, laboratory values and echocardiographic parameters are presented in Table 1.

\section{Hospital length of stay}

The median length of stay was 7 days, with the shortest hospital stay was 3 days and the longest was 45 days. There were 149 (57.5\%) patients with LOS of $\leq 7$ days, and $110(42.5 \%)$ patients with LOS of $>7$ days.

\section{Predictors of length of stay}

From univariate analysis, a longer LOS was found to be associated with higher diastolic BP (HR 1.011; 95 \% CI 1.004-1.018; $p=0.002$ ), higher hemoglobin level (HR 1.102; 95 \% CI 1.045-1.162; $p<0.001$ ), lower TAPSE (HR $0.659 ; 95 \%$ CI $0.506-0.857 ; p=0.002)$, worsening renal function (HR 2.015; $95 \%$ CI 1.520-2.670; $p<0.001$ ) and malnutrition (HR 5.965; 95 \% CI 4.402-8.082; $p<0.001$ ).

Multivariate Cox regression analysis was performed in order to investigate independent predictors of longer LOS. Nine variables with $p<0.25$ from univariate analysis were included in multivariate model (Table 2). In a multivariate Cox regression model, RV function (HR 0.466; 95 \% CI 0.238-0.915; $p=0.026$ ), WRF (HR 2.985; $95 \%$ CI 2.032-4.386; $p<0.001)$ and malnutrition (HR 7.479 ; $95 \%$ CI $5.071-11.030 ; p<0.001)$ were the independent predictors of longer hospital LOS. When we divided the TAPSE based on its median value, then TAPSE $\leq 16 \mathrm{~mm}$ remains significantly associated with longer LOS (HR 2.227; 95 \% CI 1.103-4.494; $p=0.026$ ).

\section{Discussion}

The principal findings in this study are: 1) RV dysfunction as assessed by TAPSE is an independent predictor of longer LOS, and 2) worsening renal function and malnutrition are also associated significantly with longer LOS.

Hospital LOS is increasingly used as a measure of quality care in patients admitted for acute heart failure. Longer LOS is an important outcome, both from the perspective of the patients' experience and healthcare system [28]. The optimal duration of hospital stay for treatment of an episode of decompensated heart failure remains unknown [1]. The median LOS in our study was 7 days, three days longer than in Acute Decompensated Heart Failure National Registry (ADHERE) [29], but shorter than that reported in EuroHeart Failure 
Table 1 Baseline Characteristic of Patients

\begin{tabular}{|c|c|}
\hline Variable $(N=259)$ & $\begin{array}{l}\text { Mean } \pm \text { SD/ Median } \\
(\text { min - max Number (\%) }\end{array}$ \\
\hline Age (year) & $59(18-84)$ \\
\hline \multicolumn{2}{|l|}{ Sex, n (\%) } \\
\hline Male & $194(74.9 \%)$ \\
\hline Female & $65(25.1 \%)$ \\
\hline Body mass index $\left(\mathrm{kg} / \mathrm{m}^{2}\right)$ & $23.87(12.49-49.17)$ \\
\hline Nutritional Risk Index (NRI) & $98.63 \pm 12.37$ \\
\hline \multicolumn{2}{|l|}{ Risk Factor, n (\%) } \\
\hline Hypertension & $171(66 \%)$ \\
\hline DM/Prediabetes & $157(60.6 \%)$ \\
\hline Smoking & $127(49 \%)$ \\
\hline \multicolumn{2}{|l|}{ Clinical Presentation, n (\%) } \\
\hline Acute lung edema & $19(7.3 \%)$ \\
\hline Increased JVP & $194(74.9 \%)$ \\
\hline Peripheral edema & $154(59.5 \%)$ \\
\hline \multicolumn{2}{|l|}{ Comorbidities, n (\%) } \\
\hline Pneumonia & $31(12 \%)$ \\
\hline Worsening Renal Function & $72(27.8 \%)$ \\
\hline Malnutrition & 127 (49\%) \\
\hline \multicolumn{2}{|l|}{ Heart Failure Etiology, n (\%) } \\
\hline Ischemic heart disease & $198(76.5 \%)$ \\
\hline Hypertensive heart disease & $42(16.2 \%)$ \\
\hline Other cardiomyopathy & $19(7.3 \%)$ \\
\hline \multicolumn{2}{|l|}{ ECG, n (\%) } \\
\hline Sinus rhythm & $213(82.2 \%)$ \\
\hline Atrial fibrillation & $41(15.8 \%)$ \\
\hline Others & $5(1.9 \%)$ \\
\hline \multicolumn{2}{|l|}{ Medications on Admission, n (\%) } \\
\hline Diuretics (Furosemide) & $238(91.9 \%)$ \\
\hline ACE inhibitors & $146(56.4 \%)$ \\
\hline Angiotensin receptor blockers (ARB) & $93(35.9 \%)$ \\
\hline Mineralocorticoid receptor antagonist (MRA) & $127(49 \%)$ \\
\hline Calcium channel blockers & $19(7.3 \%)$ \\
\hline Beta blockers & $120(46.3 \%)$ \\
\hline Digoxin & $47(18.1 \%)$ \\
\hline Systolic BP (mmHg) & $127(75-231)$ \\
\hline Diastolic BP (mmHg) & $78(38-159)$ \\
\hline Heart rate ( $x /$ minute) & $96(36-179)$ \\
\hline \multicolumn{2}{|l|}{ Laboratory values } \\
\hline Hemoglobin (mg/dl) & $13.3(5.8-18.8)$ \\
\hline Leukocyte (/uL) & 8780 (3390 - 29740) \\
\hline Random blood glucose (mg/dl) & $135(61-618)$ \\
\hline Albumin $(g / d l)$ & $3.5(1.8-4.5)$ \\
\hline Ureum (mg/dl) & $50(9-278)$ \\
\hline
\end{tabular}

Table 1 Baseline Characteristic of Patients (Continued)

\begin{tabular}{ll}
\hline Creatinine (mg/dl) & $1.4(0.61-10.02)$ \\
eGFR & $50(4-112)$ \\
Echocardiographic parameters & \\
End Diastolic Diameter $(\mathrm{mm})$ & $60(25-92)$ \\
End Systolic Diameter $(\mathrm{mm})$ & $52(16-83)$ \\
Ejection fraction $(\%)$ & $27(12-85)$ \\
$\geq 50 \%$ & $40(15.4 \%)$ \\
$40-49 \%$ & $27(10.4 \%)$ \\
$<40 \%$ & $192(74.1 \%)$ \\
TAPSE (mm) & $16(7-29)$ \\
$>16 \mathrm{~mm}$ & $120(46.3 \%)$ \\
$\leq 16 \mathrm{~mm}$ & $139(53.7 \%)$ \\
Mean Pulmonary Artery Pressure $(\mathrm{mmHg})$ & $25(5-50)$ \\
\hline
\end{tabular}

Survey II (EHFSII) [30] and Acute Heart Failure Acute Heart Failure Global Survey of Standard Treatment (ALARM-HF) [31].

To the best of our knowledge, our study is the first to describe that RV dysfunction is an independent predictor of longer LOS in the setting of ADHF patients. Higher TAPSE value was found to be a protective factor for longer LOS from multivariate analysis, with HR 0.466 (95\% CI $0.238-0.915 ; p=0.026$ ). Further analysis by dividing TAPSE based on its median value showed that patients with TAPSE $\leq 16 \mathrm{~mm}$ had 2.227 times higher probability for having longer hospital LOS. Although previous studies by Ghio et al [13] and Damy et al [15] have reported the prognostic value of RV dysfunction (as measured by TAPSE) with the adverse outcomes in HF patients, those studies were limited to patients with chronic HF and reduced LV function. Taken together, the findings of this study and other studies suggested that evaluation of RV function should be considered as a part of comprehensive evaluation in hospitalized ADHF and chronic HF patients, and when available, should be used to stratify those patients for prognostic and therapeutic purposes.

Table 2 Multivariate analysis of length of stay

\begin{tabular}{lll}
\hline Variable & HR $(95 \% \mathrm{Cl})$ & $p$ \\
\hline Congestion signs & $1.259(0.848-1.868)$ & 0.253 \\
Prior HT & $1.485(1.019-2.162)$ & 0.039 \\
Systolic BP & $1.000(0.990-1.009)$ & 0.927 \\
Diastolic BP & $1.006(0.994-1.019)$ & 0.333 \\
Hemoglobin & $1.041(0.970-1.117)$ & 0.261 \\
TAPSE & $0.466(0.238-0.915)$ & 0.026 \\
mPAP & $1.003(0.978-1.028)$ & 0.841 \\
Worsening renal function & $2.985(2.032-4.386)$ & $p<0.001$ \\
Malnutrition & $7.479(5.071-11.030)$ & $p<0.001$ \\
\hline
\end{tabular}


The present study strengthens the previous observations by demonstrating the feasibility of a noninvasive echocardiographic evaluation of RV function as well as its usefulness in the prognostic stratification of patients with ADHF. The superior prognostic strength of TAPSE with respect to the other echocardiographic parameters of RV systolic function is that a reduced TAPSE better reflects a severe impairment of RV performance, because the systolic shortening of the RV from base to apex provides information not only on the emptying of the RV but also on the driving force which acts on the systemic venous column [13].

In addition, our study found the prevalence of WRF was $27.8 \%$ and it confirmed previous studies that reported the occurrence of WRF to be approximately 27$34 \%[20,32]$, but it was higher than other studies that reported the prevalence of 9-15\% [33-36]. We found that WRF occured during hospitalization associated significantly with longer LOS, as also shown in other previous studies [1,9]. Wright et al [1] reported that the development of renal failure were independently associated with longer than average LOS. This is due to the fact that comorbidities such as renal dysfunction will delay patient's response to treatment, prevent the use of certain treatments and require additional time to manage [3].

Finally, we found an interesting obervation in which the prevalence of malnutrition in our ADHF patients was higher (49\%) than the study reported by Aziz et al [10] (34\% in ADHF patients in United States) and Al Najjar et al [37] (23 \% in CHF patients in United Kingdom). This high prevalence showed that malnutrition was one of the frequent comorbidities that occured in heart failure patients. Although the mechanism on how nutritional status affects the evolution of HF has not been sufficiently established, several studies has reported that malnutrition was associated with worse outcome in HF patients. Aziz et al [10] reported that lower NRI score was associated with longer hospital LOS, higher readmission and mortality rates in ADHF patients. Another study also demonstrated that NRI was an independent predictor of mortality in ambulatory patients with CHF [37]. Our study demonstrated that lower NRI scores on admission can provide valuable information about risks of extended hospitalization in ADHF patients. This result confirmed previously reported studies that malnutrition was significantly associated with increased LOS $[10,11,38-40]$.

\section{Study limitations}

Variables influencing hospital LOS in HF include a broad range of socio-cultural and economic factors outside the scope of this study. We did not assess other factors that were difficult to measure such as patients' compliance, mobility, readiness for discharge, and factors related with healthcare environment. While a biomarker NT-proBNP was not analyzed in this study because our national health insurance did not cover the cost of its examination.

We excluded patients with severe tricuspid regurgitation because the accuracy of the RV systolic parameter has not been established in such patients [41-43]. We also could not provide systolic pulmonary artery pressure (sPAP) measurement due to lack of data on inferior vena cava dilatation and collapsibility in our subjects. Furthermore, we did not assess the predictive performance of other echocardiographic indices of RV function.

\section{Conclusion}

This prospective cohort study demonstrated that RV dysfunction as assessed by TAPSE was an independent predictors of longer hospital LOS in ADHF patients. We also found high prevalence of malnutrition and worsening renal function in our study population that were significantly associated with longer LOS. Since TAPSE can be easily and reliably measured in most patients, it should therefore be considered as part of routine echocardiographic examination in hospitalized ADHF patients.

\section{Abbreviations \\ ADHF, acute decompensated heart failure; $\mathrm{Cl}$, confidence interval; $\mathrm{HR}$, hazard ratio; LOS, length of stay; MPAP, mean pulmonary artery pressure; $\mathrm{NRI}$, nutritional risk index; RV, right ventricle/ventricular; TAPSE, tricuspid annular plane systolic excursion; WRF, worsening renal function}

\section{Acknowledgements}

The authors express the gratitudes to Dr. Amiliana M Soesanto, Professor Bambang B Siswanto and Dr Rarsari Soerarso for the permission and support during the study and appreciated Dr. Setia who helped the statistical analysis.

Funding

This study is not related with industry.

\section{Availability of data and material}

When requested for the confirmation of any data in this paper, the Authors are ready to share the data and materials.

Authors' contributions

"PPDY carried out the proposal development, data collection and drafted the manuscript. SBR participated in the research idea formulation, design of the study and helped to draft the manuscript. VKPP participated in the coordination of data collection and statistical analysis. $\mathrm{NH}$ conceived of the study, and participated in its design and coordination". All authors read and approved the final manuscript.

Competing interests

All authors declare that we have no competing interests.

Consent for publication

All authors and participants have signed consent for publication.

Ethics approval and consent to participate

This study has been approved by the Ethics Committee for Medical Research, National Cardiovascular Center Harapan Kita on January 14, 2015, No: LB.05.01.1.4/04/2015.

All participants have signed a consent to participate in the study. 


\section{Author details}

Department of Cardiology and Vascular Medicine, Faculty of Medicine, Universitas Indonesia, National Cardiovascular Center Harapan Kita, J. Letjend. S. Parman Kav 87, Slipi, Jakarta 11420, Indonesia. ${ }^{2}$ Department of Cardiology, Gatot Subroto Army Hospital, Jakarta, Indonesia.

Received: 29 February 2016 Accepted: 5 July 2016

Published online: 11 July 2016

\section{References}

1. Wright SP, Verouhis D, Gamble G, Swedberg K, Sharpe N, Doughty RN. Factors influencing the length of hospital stay of patients with heart failure. Eur J Heart Fail. 2003:5:201-9.

2. Allen LA, Smoyer Tomic KE, Wilson KL, Smith DM, Agodoa I. The inpatient experience and predictors of length of stay for patients hospitalized with systolic heart failure: comparison by commercial, Medicaid, and Medicare payer type. J Med Econ. 2013;16:43-54.

3. Whellan DJ, Zhao X, Hernandez AF, et al. Predictors of hospital length of stay in heart failure: findings from Get With the Guidelines. J Card Fail. 2011; 17:649-56.

4. Gheorghiade M, Pang PS. Acute heart failure syndromes. J Am Coll Cardiol. 2009;53:557-73.

5. Krantz MJ, Tanner J, Horwich TB, et al. Influence of hospital length of stay for heart failure on quality of care. Am J Cardiol. 2008;102:1693-7.

6. $\mathrm{Ni} \mathrm{H}$, Nauman DJ, Hershberger RE. Analysis of trends in hospitalizations for heart failure. J Card Fail. 1999:5:79-84.

7. Burns LR, Wholey DR. The effects of patient, hospital, and physician characteristics on length of stay and mortality. Med Care. 1991;29:251-71.

8. Harjai KJ, Nunez E, Turgut T, et al. The independent effects of left ventricular ejection fraction on short-term outcomes and resource utilization following hospitalization for heart failure. Clin Cardiol. 1999;22:184-90.

9. Brown AM, Cleland JG. Influence of concomitant disease on patterns of hospitalization in patients with heart failure discharged from Scottish hospitals in 1995. Eur Heart J. 1998;19:1063-9.

10. Aziz EF, Javed F, Pratap B, et al. Malnutrition as assessed by nutritional risk index is associated with worse outcome in patients admitted with acute decompensated heart failure: an ACAP-HF data analysis. Heart Int. 2011;6:e2.

11. Kyle UG, Schneider SM, Pirlich M, Lochs H, Hebuterne X, Pichard C. Does nutritional risk, as assessed by Nutritional Risk Index, increase during hospital stay? A multinational population-based study. Clin Nutr. 2005;24:516-24.

12. Gajanana D, Seetha Rammohan H, Alli O, et al. Tricuspid Annular Plane Systolic Excursion and Its Association with Mortality in Critically III Patients. Echocardiography. 2015

13. Ghio S, Recusani F, Klersy C, et al. Prognostic usefulness of the tricuspid annular plane systolic excursion in patients with congestive heart failure secondary to idiopathic or ischemic dilated cardiomyopathy. Am J Cardiol. 2000:85:837-42

14. Meluzin J, Spinarova L, Hude P, et al. Prognostic importance of various echocardiographic right ventricular functional parameters in patients with symptomatic heart failure. J Am Soc Echocardiogr: official Publication of the American Society of Echocardiography. 2005;18:435-44.

15. Damy T, Kallvikbacka-Bennett A, Goode K, et al. Prevalence of associations with, and prognostic value of tricuspid annular plane systolic excursion (TAPSE) among out-patients referred for the evaluation of heart failure. J Card Fail. 2012;18:216-25.

16. Kjaergaard J, Akkan D, Iversen KK, Kober L, Torp-Pedersen C, Hassager C. Right ventricular dysfunction as an independent predictor of shortand long-term mortality in patients with heart failure. Eur J Heart Fail. 2007;9:610-6.

17. Aronson D, Darawsha W, Atamna A, et al. Pulmonary hypertension, right ventricular function, and clinical outcome in acute decompensated heart failure. J Card Fail. 2013:19:665-71.

18. Verhaert D, Mullens W, Borowski A, et al. Right ventricular response to intensive medical therapy in advanced decompensated heart failure. Circ Heart Fail. 2010;3:340-6.

19. Ponikowski $\mathrm{P}$, Voors AA, Anker SD, et al. 2016 ESC Guidelines for the diagnosis and treatment of acute and chronic heart failure: The Task Force for the diagnosis and treatment of acute and chronic heart failure of the European Society of Cardiology (ESC) Developed with the special contribution of the Heart Failure Association (HFA) of the ESC. Eur Heart J. 2016

20. Forman DE, Butler J, Wang Y, et al. Incidence, predictors at admission, and impact of worsening renal function among patients hospitalized with heart failure. J Am Coll Cardiol. 2004;43:61-7.

21. O'Meara E, Chong KS, Gardner RS, Jardine AG, Neilly JB, McDonagh TA. The Modification of Diet in Renal Disease (MDRD) equations provide valid estimations of glomerular filtration rates in patients with advanced heart failure. Eur J Heart Fail. 2006;8:63-7.

22. Buzby GP, Knox LS, Crosby LO, et al. Study protocol: a randomized clinical trial of total parenteral nutrition in malnourished surgical patients. Am J Clin Nutr. 1988;47:366-81.

23. Pablo AM, Izaga MA, Alday LA. Assessment of nutritional status on hospital admission: nutritional scores. Eur J Clin Nutr. 2003;57:824-31.

24. Lorentz FH. Ein neuer Konstitutions index. Klin Wochenschr. 1929:8:348-51.

25. Caccialanza R, Klersy C, Cereda E, et al. Nutritional parameters associated with prolonged hospital stay among ambulatory adult patients. CMAJ: Canadian Medical Association journal = Journal de l'Association medicale canadienne. 2010;182:1843-9.

26. Oh CA, Kim DH, Oh SJ, et al. Nutritional risk index as a predictor of postoperative wound complications after gastrectomy. World Journal of Gastroenterology: WJG. 2012;18:673-8.

27. Lang RM, Badano LP, Mor-Avi V, et al. Recommendations for cardiac chamber quantification by echocardiography in adults: an update from the American Society of Echocardiography and the European Association of Cardiovascular Imaging. Eur Heart J Cardiovasc Imag. 2015;16:233-70.

28. Bueno H, Ross JS, Wang Y, et al. Trends in length of stay and short-term outcomes among Medicare patients hospitalized for heart failure, 1993 2006. JAMA. 2010;303:2141-7.

29. Adams Jr KF, Fonarow GC, Emerman CL, et al. Characteristics and outcomes of patients hospitalized for heart failure in the United States: rationale, design, and preliminary observations from the first 100,000 cases in the Acute Decompensated Heart Failure National Registry (ADHERE). Am Heart 2005:149:209-16.

30. Nieminen MS, Brutsaert D, Dickstein K, et al. EuroHeart Failure Survey II (EHFS II): a survey on hospitalized acute heart failure patients: description of population. Eur Heart J. 2006;27:2725-36.

31. Follath F, Yilmaz MB, Delgado JF, et al. Clinical presentation, management and outcomes in the Acute Heart Failure Global Survey of Standard Treatment (ALARM-HF). Intensive Care Med. 2011:37:619-26.

32. Metra M, Nodari S, Parrinello G, et al. Worsening renal function in patients hospitalised for acute heart failure: clinical implications and prognostic significance. Eur J Heart Fail. 2008;10:188-95.

33. Damman K, Van Veldhuisen DJ, Navis G, et al. Tubular damage in chronic systolic heart failure is associated with reduced survival independent of glomerular filtration rate. Heart. 2010;96:1297-302.

34. Lassus JP, Nieminen MS, Peuhkurinen $K$, et al. Markers of renal function and acute kidney injury in acute heart failure: definitions and impact on outcomes of the cardiorenal syndrome. Eur Heart J. 2010:31:2791-8.

35. Verdiani $V$, Lastrucci $V$, Nozzoli C. Worsening renal function in patients hospitalized with acute heart failure: risk factors and prognostic significances. Int J Nephrol. 2010;2011:785974.

36. Voors AA, Dittrich $\mathrm{HC}$, Massie $\mathrm{BM}$, et al. Effects of the adenosine A1 receptor antagonist rolofylline on renal function in patients with acute heart failure and renal dysfunction: results from PROTECT (Placebo-Controlled Randomized Study of the Selective Adenosine A1 Receptor Antagonist Rolofylline for Patients Hospitalized with Acute Decompensated Heart Failure and Volume Overload to Assess Treatment Effect on Congestion and Renal Function). J Am Coll Cardiol. 2011;57:1899-907.

37. Al-Najjar Y, Clark AL. Predicting outcome in patients with left ventricular systolic chronic heart failure using a nutritional risk index. Am J Cardiol. 2012:109:1315-20.

38. Kyle UG, Pirlich M, Schuetz T, Lochs H, Pichard C. Is nutritional depletion by Nutritional Risk Index associated with increased length of hospital stay? A population-based study. JPEN J Parenter Enteral Nutr. 2004;28:99-104.

39. Pathirana AK, Lokunarangoda N, Ranathunga I, Santharaj WS, Ekanayake R, Jayawardena R. Prevalence of hospital malnutrition among cardiac patients: results from six nutrition screening tools. SpringerPlus. 2014:3:412.

40. Venzin RM, Kamber N, Keller WC, Suter PM, Reinhart WH. How important is malnutrition? A prospective study in internal medicine. Eur J Clin Nutr. 2009; 63:430-6. 
41. Hsiao SH, Lin SK, Wang WC, Yang SH, Gin PL, Liu CP. Severe tricuspid regurgitation shows significant impact in the relationship among peak systolic tricuspid annular velocity, tricuspid annular plane systolic excursion, and right ventricular ejection fraction. J Am Soc Echocardiogr: official publication of the American Society of Echocardiography. 2006;19:902-10.

42. Zeineh NS, Champion HC. Utility of Tricuspid Annular Plane Systolic Excursion in the Assessment of Right Ventricular Function. PVRI Review. 2010;2:17-21.

43. Howard LS, Grapsa J, Dawson D, et al. Echocardiographic assessment of pulmonary hypertension: standard operating procedure. European respiratory Review: J Eur Respir Soc. 2012;21:239-48.

Submit your next manuscript to BioMed Central and we will help you at every step:

- We accept pre-submission inquiries

- Our selector tool helps you to find the most relevant journal

- We provide round the clock customer support

- Convenient online submission

- Thorough peer review

- Inclusion in PubMed and all major indexing services

- Maximum visibility for your research

Submit your manuscript at www.biomedcentral.com/submit
Biomed Central 